\title{
DINÁMICAS Y TENDENCIAS DE LOS ESPACIOS COMUNES DE COOPERACIÓN UNIVERSITARIA EN IBEROAMÉRICA*
}

\author{
JORGE ANTONIO QUINDIMIL LÓPEZ \\ Profesor Contratado Doctor en Derecho Internacional Público \\ Universidad de A Coruña
}

\section{INTRODUCCIÓN}

El final del siglo XX y los primeros años del siglo XXI se presentan efervescentes en ideas para crear espacios comunes de educación superior tanto a un lado y a otro del Atlántico, como también entre ambas orillas'. Así, en el continente europeo, el modelo de referencia es el Espacio Europeo de Educación Superior (EEES) ${ }^{2}$, también conocido como proceso de Bolonia desde la suscripción de su Declaración constitutiva en esta ciudad italiana el 19 de junio de 1999. A su vez, en el continente americano, si bien no existe ningún proyecto

El presente trabajo forma parte del proyecto de investigación «Convergencia eficaz de las Organizaciones Internacionales en Iberoamérica: nuevos enfoques operativos para optimizar la integración, la democracia y la gestión de crisis» (DER-2012-37359), del Ministerio de Economía y Competitividad (2013-2016).

Con todo, como señala DE CARIA PATRÍCIO, «[a] internacionalização universitária, hoje uma realidade incontornável, nao é, todavia, um processo recente. Stallivieri lembra que o caráter internacional das universidades existe desde a criação das primeiras escolas europeias na Idade Média, as universitas, que contavam com profesores e estudantes de diferentes regiões e países que se reuniam em busca de conhecimento» (DE CARIA PATRÍCIO, R.: «Cooperação universitária ibero-americana», en SOBRINO HEREDIA, J. M.; ALCAIDE FERNÁNDEZ, J.; PUREZA, J. M. (eds.): Innovación y conocimiento, IV Jornadas Iberoamericanas de Estudios Internacionales, Lisboa, 23, 24 y 25 de noviembre de 2009, Edit. Marcial Pons, Madrid-Barcelona-Buenos Aires, 2010, p. 274).

2 Se ha llegado a proponer el modelo europeo para construir el EIC de una forma casi idéntica al EEES. Véase SOLÁ i FERRANDO: Bases para un plan estratégico del EIC, junio 2007, elaborado por encargo del Consejo Universitario Iberoamericano (CUIB) y luego presentado y analizado en la Reunión de Responsables de Educación Superior, Bogotá, julio 2007. Si bien no parece haber tenido 
de alcance panamericano o interamericano ${ }^{3}$, sí existe una reciente y creciente, aunque todavía muy difusa, iniciativa para la creación de un espacio común de educación superior en América Latina, bajo el nombre de Encuentro Latinoamericano y Caribeño de Educación Superior (ENLACES) ${ }^{4}$ y con el auspicio de la UNESCO a partir de la Conferencia Regional sobre Educación Superior de 2008. Asimismo, el vínculo birregional entre ambos continentes ha sido especialmente fructífero en el impulso y consolidación de espacios comunes, tanto en su dimensión propiamente eurolatinoamericana a través del espacio común de educación superior entre América Latina y el Caribe y la Unión Europea (ALCUE) ${ }^{5}$; como, sobre todo, en su dimensión específicamente iberoamericana, con el Espacio Iberoamericano del Conocimiento (EIC) ${ }^{6}$.

Todo ello nos sitúa ante un cambio de paradigma en la cooperación internacional en materia de educación superior, donde sin duda el EEES ha tenido un papel central como catalizador del resto de espacios ${ }^{7}$, si bien alguno de ellos

una gran acogida, este documento incluye las siguientes propuestas que suponen trasuntos de los principales elementos del EEES y del Espacio Europeo del Conocimiento:

- El sistema ECTS como base para el Sistema Iberoamericano de Transferencia y Acumulación de Créditos académicos (SITAC)

- El Erasmus como base para el Erasmus iberoamericano

- Suplemento al título

- Tuning América Latina y 6x4 como modelos para la revisión de los planes de estudio

- EURYDICE para crear un sistema iberoamericano de información sobre educación superior

- El Programa Marco UE para inspirar la revisión del CYTED

3 Un proyecto de esta naturaleza pasaría por un procedimiento abierto o constituyente a modo de gran conferencia multilateral, pero hasta la fecha no ha habido ninguna conferencia al más alto nivel presidencial o ministerial destinada en exclusiva a la formulación de un «espacio común de cooperación universitaria» en todo el continente americano. Una conferencia así podría celebrarse en Lima, al contar con la Universidad más antigua de América, la Universidad Nacional Mayor de San Marcos (1551) — no sin cierta polémica con la Universidad de Santo Domingo, creada bajo el nombre de Universidad Santo Tomás de Aquino por bula papal en 1538, pero sin autorización real hasta 1558; desapareciendo en 1823 con la invasión haitiana y reapareciendo en 1914 bajo el nombre de Universidad de Santo Domingo)—. Sin embargo, como veremos infra, en el ámbito específicamente latinoamericano sí tuvo lugar un evento multilateral constituyente de un espacio de cooperación universitaria, como fue la Conferencia Regional de Educación Superior de la UNESCO de 2008 en Cartagena de Indias (CRES 2008), que dio lugar a la creación de ENLACES, al que nos referimos justo a continuación.

$4 \mathrm{http}: / / \mathrm{www}$.iesalc.unesco.org.ve/enlaces.

5 Véase, entre otros, el trabajo de FAJARDO DEL CASTILLO, T.: «El Espacio de Educación Superior de la Unión Europea con América Latina y el Caribe y la política migratoria de la Unión Europea: los requisitos de la tarjeta azul de la UE», en SOBRINO HEREDIA, J. M.; ALCAIDE FERNÁNDEZ, J.; PUREZA, J. M. (eds.): Innovación y conocimiento, cit., pp. 349-357).

6 http://www.oei.es/espacioiberoamericanodelconocimiento.htm. De este modo, América puede identificarse no sólo como el continente que presenta el mayor número de procesos de cooperación y de integración per cápita, sino que también es el escenario del mayor número de iniciativas para la creación de espacios comunes de cooperación académica.

Para un estudio de la relación, por ejemplo, entre el EEES y el Espacio Iberoamericano del Conocimiento, véase, entre otros ÁLVAREZ GARCÍA, B.; BOEDO VILABELLA, L.; ÁLVAREZ GARCÍA, A.: «Ejes del desarrollo del Espacio Iberoamericano del Conocimiento. Análisis comparativo con el Espacio Europeo de Educación Superior», en Revista Iberoamericana de Educación, 
tiene raíces más profundas que el propio espacio europeo, como es el caso del EIC al que puede considerarse de algún modo como pionero ${ }^{8}$. Sobre la base de un sólido acervo de valores e intereses iberoamericanos, la cooperación internacional se presenta como un instrumento idóneo para favorecer la creación de una comunidad académica iberoamericana, así como para propiciar los procesos de integración regional y subregional ${ }^{9}$. La Comunidad Iberoamericana se presenta de esta manera como un espacio especialmente propicio para la cooperación interuniversitaria, si bien los obstáculos de partida no son pocos ni pequeños: las asimetrías de los sistemas universitarios, la multiplicación y heterogeneidad de Universidades, sus dispares niveles de calidad, la escasez de financiación, el reducido número de doctores, las dificultades de dedicación exclusiva, la ausencia de un marco que integre las diferentes modalidades de cooperación universitaria, las consiguientes dificultades de acceso a la información o, sobre todo, la excesiva dispersión de objetivos y dependencia del voluntarismo estatal, etc. ${ }^{10}$ Con todo, es más que evidente el interés generalizado y la creciente motivación por la cooperación iberoamericana por parte de los gobiernos y de las universidades a muy diferentes niveles, especialmente en el ámbito iberoamericano, donde la cooperación universitaria en materia de educación superior se construye sobre la base del desarrollo, de la equidad y de la justicia social ${ }^{11}$.

número 57, 2011, pp. 125-143; o, para la relación entre los espacios europeo, latinoamericano e iberoamericano, véase FERNÁNDEZ LAMARRA, N.: «La convergencia de la educación superior en América Latina y su articulación con los espacios europeo e iberoamericano. Posibilidades y límites», Avaliação, Campinas, Sorocaba, SP, v. 15, n. 2, pp. 9-44, jul. 2010.

8 En efecto, los inicios de la cooperación académica en el espacio iberoamericano se remontan al año 1984 con la creación del Programa Iberoamericano de Ciencia y Tecnología (CYTED, www. cyted.org).

9 Debe destacarse también en este punto que los procesos de integración subregional también está llevando a cabo acciones muy valiosas para alcanzar espacios de cooperación universitaria en sus respectivas áreas de influencia. En ese sentido, sobresale la Comunidad Andina, como ha puesto de manifiesto ALEGRETT, A.: «El espacio subregional andino de educación superior», en SOBRINO HEREDIA, J. M.; ALCAIDE FERNÁNDEZ, J.; PUREZA, J. M. (eds.): Innovación y conocimiento, cit., pp. 335-348).

${ }_{10}$ En este sentido, pueden consultarse también los trabajos de LÓPEZ SEGRERA, F.: «Tendencias de la educación superior en el mundo y en América Latina y el Caribe», Avaliação, Campinas, Sorocaba, SP, v. 13, n. 2, pp. 267-291, jul. 2008; y de FERNÁNDEZ LAMARRA, N.: «La Universidad latinoamericana en el marco de su autonomía. Gobernabilidad, democratización, calidad e innovación», X Congreso Internacional Retos y expectativas sobre la Universidad. Gestión, autonomía y gobierno de la Universidad pública latinoamericana, Universidad de Guadalajara, octubre 2010, disponible en: http:// www.repositoriodigital.ipn.mx/handle/123456789/3772.

11 «...] el desarrollo, la equidad y la justicia social plantean la necesidad de construir un espacio iberoamericano del conocimiento que podría sustentarse en la definición solidaria de un ámbito común de educación superior, en tanto espacio cualificado de formación, lugar de producción y transferencia de conocimientos, así como de fomento de la homologación de títulos y de la movilidad académica» (Declaración de Toledo, XV Conferencia Iberoamericana de Educación, 13 de julio de 2005, apartado 9). 
Pues bien, sobre esta base, abordaré en primer lugar desde una perspectiva integrada los espacios comunes de cooperación universitaria de naturaleza o alcance iberoamericanos — esto es, el EIC, ENLACES y ALCUE—, configurándose así Iberoamérica como la región más fértil en esta materia. A continuación, me centraré, en segundo lugar, en los que tienen una dimensión propiamente iberoamericana tratando además de justificar, en mi opinión, que son los que están en mejores condiciones de partida para concretarse en el medio plazo. Me refiero en particular al EIC, en fase de consolidación, y al ENLACES, en fase creciente, frente a un ALCUE en fase menguante.

\section{I.-IBEROAMÉRICA COMO PRINCIPAL ESCENARIO DE CREACIÓN DE ESPACIOS COMUNES DE COOPERACIÓN UNIVERSITARIA}

En el tablero iberoamericano confluyen tantos proyectos de creación de espacios comunes de educación superior en y entre Europa y América que necesariamente aparecerán caracterizados y condicionados por la implicación y, en ocasiones, interacción multinivel de una amplísima variedad de actores públicos y privados, académicos, políticos, sociales y hasta empresariales. En efecto, en el impulso y construcción de espacios comunes de educación superior intervienen, a distinto nivel, casi ochenta estados y no menos de una veintena de actores y foros de diálogo y cooperación: cumbres iberoamericanas, cumbres Unión Europea, América Latina y el Caribe ${ }^{12}$, conferencias iberoamericanas, la Organización de Naciones Unidas para la Educación, la Ciencia y la Cultura (UNESCO) a través de sus cumbres y conferencias regionales y mundiales de UNESCO y del Instituto Internacional para la Educación Superior en América Latina y el Caribe (IESALC), Foros Iberoamericanos de Responsables de Educación Superior (FIRES), diversas reuniones de rectores (de universidades públicas, de universidades públicas y privadas, de universidades de la Red Universia, de asociaciones de universidades y consejos de rectores, reuniones binacionales de universida$\operatorname{des}^{13}$, de universidades latinoamericanas, eurolatinoamericanas, iberoamericanas, euroiberoamericanas, e incluso caribeñas), un sinfín de redes de Universidades, la Secretaría General Iberoamericana (SEGIB), el Consejo Universitario Iberoamericano (CUIB), la Organización de Estados Iberoamericanos (OEI), la Comunidad Andina (CAN), el Mercado Común del Sur (MERCOSUR), el Sistema de la Integración Centroamericana (SICA), la Unión de Naciones Sudame-

\footnotetext{
12 Desde el mes de enero de 2013, la Comunidad de Estados Latinoamericanos y del Caribe (CELAC) ha pasado ser la entidad que represente a América Latina y el Caribe en las Cumbres con la Unión Europea, pasando a denominarse desde entonces Cumbres UE-CELAC. De este modo, la primera Cumbre UE-CELAC tuvo lugar los días 26 y 27 de enero de 2013 en Santiago de Chile.

13 Así, por ejemplo, con ocasión de la preparación de la Cumbre Iberoamericana de Cádiz, tuvo lugar una reunión entre representantes de Universidades españolas y colombianas en septiembre de 2012, en Cádiz.
} 
ricanas (UNASUR), la Comunidad de Estados Latinoamericanos y Caribeños (CELAC), el Convenio Andrés Bello (CAB), la Unión Europea (UE), el Banco Santander a través de Universia, múltiples acciones bilaterales y multilaterales de los Estados, etc.

De este contexto que pone de manifiesto un amplio consenso y una firme voluntad de impulsar la cooperación interuniversitaria iberoamericana, asoman con facilidad dos premisas antagónicas. Por un lado, la existencia de tal multitud y heterogeneidad de actores constituye un caldo de cultivo ubérrimo para la invención, formulación y lanzamiento de propuestas de cooperación interuniversitaria, que muchas veces son más bien fruto de la euforia que de la reflexión lo que limita su viabilidad. Por otro lado, asistimos a una ineficiente dispersión de propuestas, iniciativas y programas, con las consiguientes situaciones de divergencia, de descoordinación y, en definitiva, de indeterminación de un concepto claro y eficiente de cooperación interuniversitaria y de lo que supone la creación de espacio común ${ }^{14}$.

Por ello, son innumerables las preguntas que nos asaltan: ¿Es verdaderamente posible lograr un espacio común de educación superior en cualquier latitud y, en particular, en Iberoamérica? ¿Es posible conciliar una visión homogénea, uniforme o común de cooperación interuniversitaria entre actores tan numerosos y heterogéneos? ¿Es posible reconducir todas esas dinámicas hacia un único objetivo de creación de un espacio común? ¿Cómo abordar un escenario tan plural, atomizado y heterogéneo, si aceptamos, claro está, que la armonización y la convergencia son el camino hacia la eficacia? ¿O acaso quizá el único proceso de convergencia ha de pasar por una fórmula de cooperación reticular, en red, sobre la base incluyente de estas múltiples dinámicas? No se trata más que de algunos interrogantes de muy difícil respuesta de los muchos que plantea una materia de tan difícil aprehensión ${ }^{15}$. Ahora bien, lo que sí puede afirmarse categóricamente es que no existe ninguna estrategia, ningún proceso ni ningún foro que responda a los intereses de todos los actores que tienen voz y voto en esta materia. No hay una sola mesa en torno a la

14 Ello se pone de manifiesto, por ejemplo, con el uso indiscriminado de conceptos y expresiones como «educación superior», «investigación» y «conocimiento». Por ello, utilizaré la expresión espacio común de cooperación universitaria con la intención de referirme a las distintas situaciones en las que puedan verse comprendida tanto la educación, como la investigación o el conocimiento (éste último, en general, suele utilizarse como concepto comprensivo que aúna la educación y la investigación).

15 La formulación de las premisas señaladas desemboca directamente en la necesidad de aproximarnos al concepto y al alcance de lo que debe entenderse por espacio común de cooperación universitaria. Si bien las distintas iniciativas señaladas parten de contextos muy diferentes, lo cierto es que todas ellas comparten un lenguaje común que permite extraer con facilidad los distintos elementos que integran un espacio común de educación superior. Estos elementos son, fundamentalmente, seis: movilidad, reconocimiento, acreditación, investigación, titulaciones conjuntas y redes. Todas las iniciativas de creación de espacios comunes comprenden, de un modo u otro, estos elementos. Sin duda, la movilidad es la clave de bóveda que permite desplegar cualquier iniciativa de cooperación universitaria internacional. La esencia de todo espacio común es la superación — cuando no eliminación — de fronteras que devienen permeables a flujos constantes de estudiantes, de profesores, de investigadores 
cual se sienten todos los niveles implicados, ya sean públicos o privados, nacionales, subregionales, regionales, interregionales, iberoamericanos y birregionales. En otras palabras, si ni siquiera en el procedimiento convergen todos los actores, difícilmente podrá alcanzarse un resultado final convergente y eficaz. Sin embargo, como veremos en la segunda parte de este trabajo, el EIC sí que cuenta con un procedimiento y con una arquitectura institucional que da cabida a todos los actores implicados, destacando especialmente el protagonismo directo de las universidades, que tienen un peso específico en la base ${ }^{16} \mathrm{y}$ en el desarrollo del EIC ${ }^{17}$.

e incluso de personal de administración y de servicios, dejando así establecido el punto de partida para los intercambios de experiencias académicas que nutren y dan sentido a todo espacio común de educación superior. Ahora bien, la movilidad debe venir acompañada por el correspondiente reconocimiento de los títulos, en el caso de estudiantes, y de períodos de formación, en el caso de profesores, investigadores y personal de administración y servicios. El reconocimiento supone un paso más en el crecimiento y consolidación de un espacio común pues permite potenciar la sostenibilidad y la eficacia de la movilidad, en la medida en que garantiza la rentabilidad académica del tiempo y del esfuerzo dedicados por cada miembro de la comunidad académica. En línea con el reconocimiento, otro de los elementos básicos y comunes a los distintos proyectos de cooperación universitaria internacional lo constituye el establecimiento de titulaciones conjuntas. Por lo que se refiere al ámbito iberoamericano, este elemento cobra una especial importancia en materia de programas de doctorado habida cuenta de la escasez de doctores en América Latina y del gran potencial formativo de las Universidades españolas y portuguesas. De este modo, la oferta y la demanda de programas de doctorado casan a la perfección con el espacio iberoamericano, creando así un marco especialmente idóneo para el establecimiento de programas de doctorado.

Como era inevitable, también se ha ido incorporando a la formulación de espacios comunes la investigación, dando así lugar a la noción de «espacio común de conocimiento» que incluye tanto la cooperación internacional en materia de educación superior como la cooperación internacional en materia de investigación. En el caso del EIC, la investigación ha estado precisamente en el origen de la cooperación universitaria a través de la creación del citado programa CYTED en 1984. Sin embargo, salvo esta importante excepción, la investigación no suele ser un componente previo a los espacios comunes sino que suele acompañar su creación o, al menos, suele incorporarse en sus estadios iniciales de formación. Un paso más en la creación de un espacio común lo constituye la creciente necesidad de poner en funcionamiento sistemas comunes de acreditación y de evaluación de la calidad de los distintos elementos de cada sistema universitario. Una adecuada y racional implementación de sistemas comunes de calidad permitiría crear un entorno de confianza y de armonización necesario para consolidar un espacio común de educación superior. Finalmente, no puede dejar de mencionarse un elemento fundamental, pero en gran medida informal y muy disperso y heterogéneo, como son las redes temáticas sobre áreas de interés común. Son innumerables las redes que académicos de todo el mundo, y en particular de América y de Europa, han ido creando para dar cobertura e impulsar múltiples iniciativas de investigación y de intercambio de información, así como foros de encuentro y de discusión.

16 En la Declaración Final del II Encuentro Iberoamericano de Rectores (Lima, 2001) se afirma, en su apartado 6, «que los países iberoamericanos, que comparten una tradición e identidad cultural con personalidad definida en el universo global, tienen en éstas [las Universidades iberoamericanas] un potencial movilizador e integrador que ha venido siendo aprovechado sólo parcialmente en los actuales programas e iniciativas de cooperación universitaria; que, en todo caso, es aconsejable aprovechar la experiencia ya adquirida en materia de cooperación universitaria en nuestra propia regional, así como en otras partes del mundo».

17 Así se ha reconocido al máximo nivel político por la Cumbre Iberoamericana de Asunción de 2011, donde se destacó «[1]a decisiva contribución de las Universidades al desarrollo del Espacio Iberoamericano del Conocimiento (EIC) y la firma por los representantes de los Consejos de Rectores y Redes Universitarias que integran el Consejo Universitario Iberoamericano (CUIB) de la Declaración Universitaria Iberoamericana, suscrita en Asunción, el día 10 de marzo de 2011, en la que manifiestan 
Con todo, las universidades apuestan de un modo u otro por todos los espacios que están en marcha. Por un lado, apuestan al EIC desde la Declaración del II Encuentro Iberoamericano de Rectores de Lima 2001 y de la Conferencia de presidentes de Asociaciones Iberoamericanas de Universidades de A Coruña $2002^{18}$. Por otro lado, apuestan al espacio eurolatinoamericano (ALCUE) desde la Declaración de Universidades de Europa, América Latina y el Caribe, de Guadalajara en $2004^{19}$. Y, finalmente, también apuestan al espacio latinoamericano

la necesidad de avanzar en la construcción del EIC y expresan su propósito de contribuir a ello, desde una autonomía responsable» (Marco de Acción de Asunción, 29 de octubre de 2011, apartado E.3).

18 El EIC no sólo es el que cuenta con el apoyo más dilatado en el tiempo, sino también el que cuenta con el mayor respaldo. Ello se debe a que los Rectores de la red Universia se inclinan de forma clara por el EIC al afirmar, justo antes de su presentación oficial en la Cumbre de Salamanca en 2005, que promoverán «las ideas, los programas y las modificaciones del marco normativo universitario necesarias para favorecer la movilidad de estudiantes, doctorandos, profesores e investigadores en el seno de nuestra comunidad iberoamericana» y se hace referencia al ámbito iberoamericano para impulsar la investigación, la creación de redes, los sistemas de calidad o el propio fortalecimiento de la identidad iberoamericana a través de la cooperación interuniversitaria. Por todo ello, se dirigen al CUIB para que promueva en representación de todas las Universidades iberoamericanas ante organismos multilaterales y ante las Cumbres Iberoamericanas el «diseño y puesta en marcha de un Programa Cumbre específico sobre la creación de un espacio común iberoamericano de la educación superior y la investigación» (Documento de Conclusiones del I Encuentro Internacional de Rectores de Universia, Sevilla, 20 mayo 2005). Con el patrocinio del Banco Santander, Universia es la mayor red de universidades de habla hispana y portuguesa, formada por 1.216 instituciones educativas presentes en 23 países y que representan a 11,2 millones de alumnos y 888.500 profesores (www.universia.net). Hay que recordar que en 2010 el Banco Santander, en el II Encuentro de Rectores, anunció 600 millones de euros en 5 años para cooperación interuniversitaria. La Cumbre Iberoamericana de Mar del Plata de 2010 decidió incorporar como agente del EIC a Santander Universidades (Universia), consumando así una triple relación de mutuo interés entre el nivel político, académico y financiero (Programa de Acción de Mar del Plata, apartado 24).

19 En la Declaración de Guadalajara se muestran «conscientes del potencial del trabajo en común que tienen todas ellas [UE - ALC] y expresan su convencimiento de que es posible crear un espacio integrado, que favorezca la compatibilidad y comparabilidad de los sistemas de educación superior, y lograr una mayor movilidad de estudiantes, profesores y gestores que genere una mayor cultura en común...» (párrafo segundo). Se felicitan de que en las Cumbres UE-ALC siempre se haya prestado especial atención al tema universitario desde 1999, fijando el compromiso de establecer una sólida colaboración en el ámbito educativo y fomentar los intercambios interregionales de los actores, y en la II Cumbre de 2002, proponiendo un plan de acción para construir un espacio común de educación superior UE-ALC (párrafo tercero). Sin embargo, señalan que programas como Alfa o Alban, aun siendo una «buena aportación» a la cooperación interuniversitaria, tienen «un valor testimonial» debido a su baja dotación presupuestaria (el programa Alfa estuvo dotado con 160 millones de euros entre 1994-2013). En este sentido, «confían en que los jefes de Estado y de gobierno puedan poner en marcha en la Cumbre de Guadalajara las acciones pertinentes para que la Comisión de la UE, presente en la IV Cumbre, a celebrar en Austria en 2006, un nuevo programa de envergadura, que dé satisfacción al gran reto de la vinculación universitaria que el espacio UE-ALC tiene planteado» (párrafo quinto in fine).

En refuerzo de la creación de este espacio eurolatinoamericano en la Cumbre UE-ALC de Viena 2006, el CUIB y la Asociación Europea de Universidades (EUA), se reunieron en Oviedo los días 10 y 11 de abril de 2006 para proponer prioridades y líneas de acción a los gobiernos en una Declaración Final para ser elevada a la Cumbre de Viena. Ya en el Convenio Marco de Colaboración CUIB-EUA (27 mayo 2004) se deja constancia de ambas instituciones «de establecer una relación formal de colaboración que tenga como objetivo principal aunar esfuerzos en pro de la construcción de un espacio común de la ES y de la investigación, un espacio común del conocimiento, UE-ALC. Ambas organizaciones comparten la opinión de que la educación, la ciencia y la cultura son las fuerzas que impulsan la equidad, el progreso social y el crecimiento económicos» (apartado IV). Esto es posible porque si bien 
y caribeño (ENLACES) desde la Conferencia Regional de Educación Superior de la UNESCO de 2008 (CRES 2008) en la que se sentaron las bases del nuevo espacio ENLACES ${ }^{20}$. Los participantes ${ }^{21}$ en la CRES 2008 situaron la creación de ENLACES en el primer orden de prioridades para América Latina: «La integración académica latinoamericana y caribeña es una tarea impostergable. Es necesaria para crear el futuro del Continente [...] Tenemos la obligación y la responsabilidad de crear un futuro propio» ${ }^{22}$. Ello puede ser un claro ejemplo de

el objetivo principal del CUIB según su Protocolo de Constitución es «promover la creación y consolidación de un Espacio Iberoamericano de la ES y la Investigación» (apartado 3, párrafo primero), se le atribuye en segundo lugar el de «impulsar la cooperación entre universidades iberoamericanas y con universidades de otras regiones» (apartado 3, párrafo segundo). De ahí que el CUIB sirva para un roto y para un descosido: con la EUA fomenta la creación del espacio ALCUE y con la OEI fomenta la del EIC.

${ }^{20}$ «Es fundamental la construcción de un Espacio de Encuentro Latinoamericano y Caribeño de Educación Superior (ENLACES), el cual debe formar parte de la agenda de los gobiernos y los organismos multilaterales de carácter regional. Ello es básico para alcanzar niveles superiores que apunten a aspectos fundamentales de la integración regional: la profundización de su dimensión cultural; el desarrollo de fortalezas académicas que consoliden las perspectivas regionales ante los más acuciantes problemas mundiales; el aprovechamiento de los recursos humanos para crear sinergias en escala regional; la superación de brechas en la disponibilidad de conocimientos y capacidades profesionales y técnicas; la consideración del saber desde el prisma del bienestar colectivo; y la creación de competencias para la conexión orgánica entre el conocimiento académico, el mundo de la producción, el trabajo y la vida social, con actitud humanista y responsabilidad intelectual» (CRES 2008, Cartagena de Indias, 4-6 de junio de 2008, Declaración, p. 9. Véase también el Plan de Acción CRES 2008.). Asimismo, entre las distintas acciones que se establecen como necesarias para la consolidación de ENLACES, pueden identificarse las siguientes que, por lo demás, responden también a los elementos que establecimos como inherentes a los espacios comunes de cooperación universitaria:

- La renovación de los sistemas educativos de la región, con el objeto de lograr una mejor y mayor compatibilidad entre programas, instituciones, modalidades y sistemas, integrando y articulando la diversidad cultural e institucional;

- La articulación de los sistemas nacionales de información sobre ES, a través del Mapa de Educación Superior de AL (MESALC), el mutuo conocimiento entre los sistemas como base para la movilidad

-El fortalecimiento del proceso de convergencia de los sistemas de evaluación y acreditación

-El mutuo reconocimiento de estudios, títulos y diplomas, sobre la base de garantías de calidad, así como la formulación de sistemas de créditos académicos comunes aceptados en toda la región.

-El fomento de la movilidad intrarregional de estudiantes, investigadores, profesores y personal administrativo, incluso a través de la implementación de fondos específicos.

-El emprendimiento de proyectos conjuntos de investigación y la creación de redes de investigación y docencia multiuniversitarias y pluridisciplinarias.

-El impulso a programas de educación a distancia.

-El fortalecimiento del aprendizaje de lenguas de la región para favorecer una integración regional que incorpore como riqueza la diversidad cultural.

21 A la Conferencia asistieron más de 3.500 académicos, investigadores, representantes de los gobiernos, estudiantes y otros actores vinculados a la enseñanza superior de toda América Latina, siendo así la primera región del mundo en organizar una conferencia específica sobre la educación superior.

22 Declaración CRES 2008, Cartagena de Indias, 6 de junio de 2008, p. 10. La CRES 2008 encomendó al IESALC designar una comisión encargada de presentar a la brevedad una hoja de ruta que permita la integración progresiva de las instituciones de Educación Superior de la región. Luego, en el III Encuentro de Redes Universitarias y Consejos de Rectores de ALC (Lima, 1-2 junio 2009), se llegó al acuerdo de crear una plataforma de encuentro para las instituciones de educación superior y se explicitó el acuerdo de construir [ENLACES] basado en los principios de solidaridad, autonomía y cooperación, y se delinearon las primeras propuestas concretas de cooperación universitaria. Para ello 
que «los países latinoamericanos priorizan el refuerzo de los lazos endógenos en un panorama donde la educación superior se enmarca dentro de las prioridades de los nuevos procesos de integración en América Latina, tales como a Unión de Naciones Sudamericanas (UNASUR) o la Alternativa Bolivariana para América Latina y el Caribe (ALBA)»²3.

Ahora bien, a pesar de la aparente fortaleza que parece mostrar ENLACES en su planteamiento inicial, lo cierto es que adolece de una gran debilidad que es la falta de institucionalización. Hasta la fecha, el respaldo y el fortalecimiento institucional de ENLACES se han buscado a través de la doble vía de la OEA, primero, y de la CELAC, después. Al año siguiente a la CRES 2008, las organizaciones y redes universitarias de América Latina y el Caribe, promovidas por el IESALC con la finalidad de ratificar e impulsar ENLACES, hicieron «un llamado a la OEA y a las organizaciones financiera internacionales, para apoyar los programas y acciones relativos a la educación superior ${ }^{24}$ solicitando además «que la Cumbre de las Américas de Trinidad y Tobago [de 2009] incluyese el apoyo explícito a ENLACES $»^{25}$. Más recientemente, los días 5 y 6 de mayo de 2011, se celebró en Buenos Aires el IV Encuentro de Redes Universitarias y Consejos de Rectores en ALC, teniendo por objeto principal el fortalecimiento de ENLACES, para lo que

se creó una comisión de seguimiento con la finalidad de elaborar una agenda de trabajo y establecer los ejes de acción, con el apoyo de IESALC. La Comisión Interuniversitaria Nacional argentina hizo suya en 2009 la Declaración de Lima 2009, asumió el Plan de Acción CRES 2008 y el de ENLACES y ofreció su colaboración a IESALC y a la Comisión de Seguimiento para desarrollar la iniciativa (Acuerdo Plenario $\mathrm{n}^{\circ} 703 / 09$, Comisión Interuniversitaria Nacional, Comisión de Asuntos Internacionales, Villa María, 18 de septiembre de 2009).

${ }^{23}$ SOTILLO, J. A.; RODRÍGUEZ, I.; ECHART, E.; OJEDA, T.: El Espacio Iberoamericano de Educación Superior: Diagnóstico y propuestas institucionales, Edit. Fundación Carolina - CeALCI, Madrid, 2009, p. 30.

24 Declaración de Santo Domingo, 10 de marzo de 2009, apartado 2.3.

25 Declaración de Santo Domingo, 10 de marzo de 2009, apartado 2.4. Finalmente, la Cumbre de Trinidad y Tobago no recogió este apoyo explícito a ENLACES que se solicitaba. Con todo, al año siguiente se celebró precisamente en el Caribe la I Conferencia Caribeña de Educación Superior, entre los días 11 y 13 de abril de 2010 en Surinam, donde se volvió a insistir en la necesidad de contar con el respaldo de la OEA. En concreto, se afirmó que desde un punto de vista institucional u operativo, el «Mecanismo del 'Encuentro de Ministros de Educación de la OEA' debe ser usado para apoyar la alianza efectiva entre AL y el Caribe y promover la total participación de los Ministros de Educación de la Región» (Declaración de Paramaribo, apartado VI.3). Por lo demás, esta Conferencia giró en torno a la proyección del Caribe en materia de cooperación universitaria con el resto de América Latina, sobre la base de los principios de inclusión y de diferenciación. Se involucra también la integración caribeña en el educación superior señalando que «los Estados Miembros del CARICOM deben proveer los mecanismos necesarios para establecer los organismos nacionales de acreditación en el marco de la integración regional» (apartado II.4). Asimismo, «una mayor cooperación regional entre América Latina y el Caribe es deseable tal como el reconocimiento de calificaciones, aseguramiento de la calidad y armonización de estándares para promover la movilidad académica y profesional» (apartado II.5). Se apela también a «todas las Instituciones de educación superior del Caribe y de América Latina a buscar activamente oportunidades de cooperación entre ellas, construyendo sobre las fortalezas existentes, en las redes regionales y con las organizaciones regionales e internacionales. Todos estos mecanismos son esenciales para la integración regional y la internacionalización, y deben 
se adoptaron una serie de acuerdos ${ }^{26}$ (a modo de hoja de ruta para el desarrollo de ENLACES) entre los que se señala la necesidad de «contar con una instancia institucional de acuerdo político, por lo que se alienta la creación de una mesa de acuerdo, que reúna a las Conferencias de Rectores Latinoamericanos-Caribeños. Un factor llamado a reforzar esta intencionalidad debiera ser la Comunidad de Naciones de Latinoamérica y el Caribe» ${ }^{27}$. De esta forma, se está apelando a la imbricación de ENLACES con la Comunidad de Estados de Latinoamérica y el Caribe (CELAC) in status nascenti. En consecuencia, el principal problema de ENLACES radica que la ausencia de un marco institucional de naturaleza política en el que desarrollarse por lo que las diversas propuestas formuladas corren el riesgo de caer sencillamente en saco roto, a la espera de que pueda recogerlas alguna organización internacional, como la OEA o la CELAC, por ejemplo.

En este contexto, ENLACES busca también su fortalecimiento a través del establecimiento de un vínculo directo con el EIC, pudiendo llegar a encontrar en

ser parte de una agenda de los gobiernos de la región, agencias multilaterales e instituciones académicas y privadas» (apartado IV.5). Finalmente, la última consideración de la Declaración es elocuente en el sentido de propugnar la construcción de un espacio común propio para América Latina y el Caribe: «La integración de América Latina y el Caribe es necesaria para poder crear el futuro de la región y del Continente y no puede ser postergada. La reunión de Paramaribo no puede concluir sin comprometerse a sí misma en asegurar esta meta. Tenemos que reiterar la obligación y la responsabilidad de crear nuestro propio futuro» (apartado IX, párrafo segundo).

26 Estos acuerdos, que constituyen una suerte de hoja de ruta para el establecimiento de ENLA$\mathrm{CES}$, se refieren a los distintos elementos que integran un espacio común, destacando además su estrecha vinculación con los procesos de integración, rasgo que también caracteriza al EIC, como veremos en el siguiente apartado. En efecto, la Declaración de Buenos Aires, de 6 de mayo de 2011, apunta las siguientes prioridades (pp. 2-3):

- La construcción de ENLACES «debe contemplar la interacción con todos los esquemas sociopolíticos que existen en ALC, especialmente con aquellos que ha concebido mecanismos de movilidad académica y de cooperación científica. Requiere asimismo un conjunto de acuerdos estratégicos, de un marco programático común y de instrumentos institucionales».

-Para ello, se necesita «la coordinación entre los Ministerios de ES y de la alianza estratégica entre las Redes y Consejos de Rectores en torno a un protocolo regional de articulación de la movilidad académica».

— «Es de vital importancia el concurso de los Parlamentos Regionales, Subregionales y Nacionales, para que incorporen a sus agendas el diseño de mecanismos legislativos, que sustente la circulación de las personas y el reconocimiento de los estudios de programas formales de las instituciones de la región».

— «La importancia de la integración regional y de la educación en general, y en ella la de la ES, es siempre enfatizada en el discurso público, por lo que corresponde una inversión mayor de parte de los gobiernos de la región para los programas de movilidad. A ello se sumará un programa de movilidad estudiantil y docente — académico y científico-, diseñado desde este espacio y coordinado por IESALC, sobre la base de experiencias exitosas.

— «El siguiente paso será la elaboración de un programa de fortalecimiento de los posgrado y los doctorados, con énfasis en posgrados conjuntos para el próximo bienio»

— «[s]e desarrollarán programas de fortalecimiento de la participación de los pueblos originarios y los afrodescendientes en la ES y se fomentará que la ES sea más pertinente con la diversidad cultural de las sociedades latinoamericanas»

—Todas las propuestas «tomarán en cuenta a las minorías, los sectores vulnerables y las personas con capacidades diferentes».

27 Declaración de Buenos Aires, 6 de mayo de 2011, apartado 9. 
la CRES 2008 al menos tres recomendaciones dirigidas a los Estados para que permitan crear sinergias entre ambos procesos ${ }^{28}$. Sin embargo, no se incluye dentro de las prioridades la creación de un espacio eurolatinoamericano, pues se señala que «es preciso fortalecer la cooperación de América Latina y el Caribe con las otras regiones del mundo, particularmente la cooperación Sur-Sur y, dentro de ésta, con los países africanos ${ }^{29}$. Todo ello nos sitúa ante una suerte de trinomio en el que el espacio ALCUE parece haber sido preterido en el momento del lanzamiento de ENLACES, por el que apuestan de forma decidida los múltiples y distintos actores de la región, junto con el EIC que, como hemos adelantado y desarrollaremos a continuación, ocupa una posición de privilegio por su dilatada y fructífera experiencia, por su solidez institucional y por su interrelación tanto con ALCUE como con ENLACES.

\section{II.-EL ESPACIO IBEROAMERICANO DEL CONOCIMIENTO COMO PARADIGMA DE COOPERACIÓN UNIVERSITARIA}

Sobre estas bases, como adelantábamos, quizá la principal idea-fuerza en este ámbito viene dada por establecer el alcance o la viabilidad de los espacios comunes de cooperación universitaria en marcha, sobre la base de una suerte de determinismo académico para establecer cuál o cuáles de los procesos en ciernes están en mejores condiciones para consolidarse. No parece muy razonable ni eficiente que puedan simultanearse todos los espacios que están en marcha o en diseño en el nivel iberoamericano, en el nivel latinoamericano con el Caribe, en el nivel latinoamericano sin el Caribe, en el nivel propiamente caribeño, en el nivel eurolatinoamericano o incluso en el nivel sudamericano ${ }^{30}$.

\footnotetext{
28 Esta relación entre ENLACES y el EIC se contempla, en primer lugar, en relación con el diseño del Mapa de la Enseñanza Superior en América Latina y el Caribe (MESALC) y con su implantación en la región (Programa de Acción CRES 2008, p. 2). En segundo lugar, se solicita a UNESCO-IESALC que «[h]aga contactos, entre otros actores, con las redes y asociaciones universitarias de la región, organismos como CAN, ALBA, MERCOSUR, CAB, RIACES, CARICOM, SICA, Espacio Iberoamericano de Conocimiento, SELA, proyectos como TUNING y $6 \times 4$, universidades y programas regionales como la UWI, UNILA, Universidad del Sur, FLACSO, CLACSO, CYTED/RICYT, solicitando que expliciten las actividades específicas que decidan adelantar en el marco de este Plan de Acción, para la articulación de esfuerzos en la región» (Plan de Acción CRES 2008, p. 9). Y, en tercer lugar, se solicita «a la OEI que sean incluidos los temas de la CRES en la Cumbre Iberoamericana de Jefes de Estado; en particular las recomendaciones del presente Plan de Acción» (ídem).

29 Declaración CRES 2008, Cartagena de Indias, 6 de junio de 2008, p. 10.

30 Si bien en UNASUR no ha habido todavía desarrollo alguno para crear un espacio común de cooperación universitaria sudamericano, sí se ha encomendado al Grupo de Trabajo Especializado en Educación que realice «todas las gestiones necesarias con MERCOSUR, CAN y otros organismos regionales, para el diseño de planes de trabajo conjuntos como herramientas válidas para la integración suramericana», y ello con el objetivo «de armonizar las agendas y evitar la duplicidad de acciones» (III Reunión de Ministros y Ministras de Ciencia, Tecnología e Innovación del Consejo Suramericano de Educación, Cultura, Ciencia, Tecnología e Innovación, Declaración de Montevideo, 22 de noviembre de 2011, apartado 5).
} 
A priori, quizá el mejor criterio objetivo para aventurarse a afirmar cuál de ellos debería prosperar y consolidarse sería el ámbito geográfico, pudiendo concluir que el mejor de los espacios comunes sería el que alcanzase a un mayor número de personas. Obviamente, ello inclinaría la balanza de forma concluyente por el espacio eurolatinoamericano. Ahora bien, debemos descartar de inmediato esta sugerencia simplista habida cuenta de las dinámicas que han venido impulsando los distintos espacios permiten concluir que el EIC es el que goza de las mejores condiciones para consolidarse como el modelo de referencia, en la medida en que presenta más y mejores elementos de consolidación, al menos hasta la actualidad ${ }^{31}$.

\section{1.-LA SÓLIDA FUNDAMENTACIÓN DEL EIC}

Una de las críticas más recurrentes en relación con la Comunidad Iberoamericana de Naciones en general, y con el proceso de cumbres en particular, es la de su escasa productividad en términos de resultados concretos ${ }^{32}$, señalando que más bien adolecen de un exceso de verbalismo, llegando por momentos a lo literario ${ }^{33}$. Ahora bien, al hablar del EIC hay que relativizar en cierta medida este verbalismo, pues son varios e importantes los logros concretos que se han alcanzado y, desde luego, superiores a los alcanzados en los espacios latinoamericano o eurolatinoamericano. Así, cuando en la Cumbre de Salamanca de 2005 se adopta por vez primera el compromiso de avanzar hacia la creación del EIC, en conexión con el incremento de la productividad y de la competitividad internacional de la región, ya se venía avanzando bastante en este camino. En efecto, más de veinte años antes, en 1984, se había puesto en marcha el Programa Iberoamericano de Ciencia y Tecnología para el Desarrollo (CYTED) que sitúa por tanto la raíz última del actual EIC en la cooperación en materia de investigación, y no propiamente de educación superior; el cual, desde 1993, organiza

31 El estudio más completo realizado sobre el EIC es el de SOTILLO, J. A.; RODRÍGUEZ, I.; ECHART, E.; OJEDA, T.: El Espacio Iberoamericano de Educación Superior: cit. Entre otros, véase también el trabajo de ACOSTA SÁNCHEZ, M. A.; REMI NJIKI, M.: «El Espacio Iberoamericano del Conocimiento: programas, proyectos y redes», en SOBRINO HEREDIA, J. M.; ALCAIDE FERNÁNDEZ, J.; PUREZA, J. M. (eds.): Innovación y conocimiento, cit., pp. 321-333.

32 Éstas críticas son, por lo demás, idénticas a las que se vierten constantemente en relación con la propia realidad latinoamericana, desde la perspectiva de la integración por ejemplo, afirmándose que son procesos que nacen, se multiplican y se reinventan, pero difícilmente llegan a logros concretos.

33 Pues bien, en materia de espacios comunes de educación superior, lo literario no sólo llega a estar presente en sentido figurado, sino incluso de forma expresa, como en la Declaración final CRES 2008, en la que, tras comprometerse a establecer un modelo propio latinoamericano y caribeño de integración académica -ENLACES-, se concluye parafraseando la obra Cien años de soledad, al afirmar que «toca avanzar hacia 'una nueva y arrasadora utopía de la vida, donde nadie pueda decidir por otros hasta la forma de morir, donde de veras sea cierto el amor y sea posible la felicidad, y donde las estirpes condenadas a cien años de soledad tengan por fin y para siempre una segunda oportunidad sobre la tierra'» (Declaración CRES 2008, in fine). O así también en la Declaración final del VI FIRES, Cádiz de 27 de julio de 2012, que concluye diciendo: «Hace 200 años el mar nos unió, 200 años después caminemos unidos por las calles del mar y avancemos por las rutas del conocimiento». 
anualmente y de manera conjunta con el Organismo Signatario - responsable nacional de Ciencia y Tecnología- del país sede, las Conferencias Científicas preparatorias de las Cumbres Iberoamericanas. La importancia creciente de este Programa da lugar a su consolidación en el año 1995 gracias a su inclusión formal entre los Programas de Cooperación de las Cumbres Iberoamericanas.

Desde ese primigenio año 1984, no dejaron de concretarse iniciativas y acciones de cooperación universitaria iberoamericana que constituyen el germen del actual EIC. Así, tras la acción en materia de investigación que supone el Programa CYTED, la segunda gran acción iberoamericana de cooperación universitaria se desplegó en el ámbito propiamente educativo, impulsando la movilidad a través del Programa Mutis creado en 1992 34 ; y a ella le siguió en 2003 la Red Iberoamericana para la Acreditación de la Calidad de la Educación Superior (RIACES), que constituye una asociación de entidades de evaluación y acreditación de la calidad de la educación superior en Iberoamérica ${ }^{35}$. De este modo, se ha ido fraguando un espacio iberoamericano volcado en la cooperación universitaria desde hace casi tres décadas y que no ha ido dejando de crecer en virtud del sinfín de asociaciones y redes de Universidades que se han ido creando en su seno y a su alrededor ${ }^{36}$.

34 Si bien es la segunda gran acción de cooperación universitaria iberoamericana, es la primera que surge como fruto del entonces recién estrenado proceso de Cumbres Iberoamericanas iniciado en México en 1991 con la Cumbre de Guadalajara. En esta I Cumbre Iberoamericana se establecieron la necesidad de diseñar programas específicos de cooperación universitaria sobre la base de prioridades en áreas establecidas por los gobiernos de las que se derivasen beneficios individualmente y para el conjunto. De esa forma se pretendía avanzar en el establecimiento de un «mercado común del conocimiento». Entre los años 1992 y 1994 se fue consolidando la idea de impulsar la cooperación a través de la movilidad y se creó el programa de Becas de posgrado Mutis, que en la actualidad se convocan a través de las becas AECID.

35 Puede accederse a toda la información sobre RIACES a través de su portal www.riaces.org.

36 Así, por ejemplo, en el estudio sobre la cooperación universitaria realizado por la Secretaría de Cooperación Iberoamericana-SECIB-, al que nos referiremos un poco más adelante, se habían analizado «quince organizaciones y asociaciones universitarias, de diferente alcance. De ámbito iberoamericano: la Asociación Universitaria Iberoamericana de Postgrado (AUIP) y la Asociación Iberoamericana de Educación Superior a Distancia (AIESAD). En el ámbito latinoamericano: la Unión de Universidades de América Latina (UDUAL), la Red de Universidades Regionales Latinoamericanas (UREL), la Asociación de Universidades de América Latina asociadas a la Compañía de Jesús (AUSJAL) y la Asociación de Universidades de América Latina y del Caribe para la Integración (AUALCPI). Las de carácter subregional son: la Asociación de Universidades Amazónicas (UNAMAZ), la Asociación de Universidades del Grupo Montevideo (AUGM), el Consejo de Rectores por la integración de la sub-región Centro Oeste de Sudamérica (CRISCOS) y el Consejo Superior Universitario Centroamericano (CSUCA). Con cobertura eurolatinoamericana están: la Asociación Columbus y el Centro Interuniversitario de Desarrollo (CINDA). Las Universidades del Grupo de Tordesillas (GT) integran tres países: Brasil, España y Portugal y, finalmente, de ámbito hemisférico: la Organización Universitaria Interamericana (OUI) y el Consejo Universitario Interamericano para el Desarrollo Económico y Social (CUIDES)» (SECIB: Análisis y potencialidades de la cooperación universitaria iberoamericana, 2001, apartado 6, párrafo octavo). Aunque la SECIB deja constancia del valor asimétrico de estas organizaciones, también hace hincapié en sus grandes virtudes, entre las que se destacan «la concreción y autolimitación de los objetivos, el número de afiliados, el fuerte compromiso institucional de los asociados, la existencia de un liderazgo y de una gestión dinamizadora, dedicada y eficaz, la idoneidad de los instrumentos para la cooperación y las capacidades financieras» (ídem). 
En otro orden de cosas, debe recordarse que las iniciativas de espacios comunes de cooperación universitaria que han venido surgiendo hasta la fecha no suelen basarse en ningún estudio sesudo o en ningún proceso de reflexión acerca de la realidad universitaria sobre la que se quieren proyectar, sino que nacen pura y llanamente de la espontánea voluntad política. Sin embargo, en cierta medida el EIC es una excepción, pues su creación en 2005 vino precedida por un estudio previo que la Cumbre Iberoamericana de Panamá ${ }^{37}$ encargó a la entonces recién creada Secretaría de Cooperación Iberoamericana (SECIB) $)^{38}$, que finalmente sería acogido por la Cumbre Iberoamericana de Lima en $2001^{39}$, así como por las propias universidades pues, aunque no fuese un documento dirigido a ellas, decidieron pronunciarse al respecto apoyando de forma contundente la creación de un programa iberoamericano de cooperación interuniversitaria, lo que constituye un claro precedente del EIC. En efecto, en el II Encuentro Iberoamericano de Rectores se hizo especial hincapié en «la necesidad de consolidar las iniciativas en materia de cooperación por medio de un Programa-Marco que, elaborado, gestionado y revisado con la participación preponderante de las universidades, debería incluir mecanismos de carácter multilateral que confieran organicidad a los esfuerzos conjuntos [...] y que compensen solidariamente los desequilibrios estructurales ${ }^{40}$. En esta línea, la segunda propuesta ${ }^{41}$ de los Rectores plantea «[1]a pronta creación de un programa iberoamericano de cooperación interuniversitaria con la significativa participación de las universidades y cuya adecuada financiación debería quedar garantizada mediante la aprobación, por la Cumbre, de un fondo especial para este fin $»^{42}$. Ese «programa iberoamericano» 0 «Progra-

\footnotetext{
37 «32. Encomendamos a la SECIB un estudio de las posibilidades y perspectivas de colaboración en el campo de la cooperación interuniversitaria, a los efectos de analizar su posible incorporación a la agenda de la cooperación iberoamericana» (Declaración de Panamá, 18 de noviembre de 2000).

${ }_{38}$ Creada sobre la base del Convenio para la Cooperación en el marco de la Conferencia Iberoamericana (Convenio de Bariloche) de 15 de octubre de 1995, y en virtud de la dispuesto en el artículo 3 del Protocolo a dicho Convenio de 15 de noviembre de 1999, la SECIB tendría así como uno de sus primeros cometidos el de analizar las posibilidades de creación de un espacio común de cooperación universitaria iberoamericana, concretándose en el informe «Análisis y potencialidades de la cooperación iberoamericana en educación superior».

39 «Recibimos con beneplácito el estudio sobre posibilidades y perspectivas de colaboración en el marco de la educación superior, que servirá de base para futuras iniciativas de cooperación interuniversitaria iberoamericana» (Declaración de Lima de 24 de noviembre de 2001, apartado 62, último párrafo).

40 Declaración final, Lima, 23 de septiembre de 2001, apartado 7.

${ }^{41}$ La primera propuesta de la Declaración se refiere a la inclusión de la educación superior en la agenda de las Cumbres Iberoamericanas «como expresión de su voluntad política de impulsar la construcción de un espacio académico iberoamericano» (Propuesta 1. La cursiva es añadida).

42 A su vez, los rectores proponen algunas características de ese programa iberoamericano de cooperación:

- Centrar sus objetivos en temas del mayor impacto social y efecto multiplicador (eliminación de pobreza, medio ambiente, desarrollo científico, mejora de la calidad de vida y formación de docentes a todos los niveles.

-Estructura organizativa flexible, no burocrática y que permita una representación directa y plural de las Universidades.
} 
ma-Marco» bien podría ser el actual EIC, en el que incluso las Universidades al alcanzado una «significativa participación» con la incorporación del CUIB a la Unidad Coordinadora del EIC.

Este impulso de los rectores al entonces denominado «espacio académico iberoamericano» cogió más fuerza al año siguiente en la ciudad de A Coruña, en la que, en el marco de la Conferencia de presidentes de Asociaciones Iberoamericanas de Universidades ${ }^{43}$, se decidió «promover la constitución permanente de un Consejo Universitario Iberoamericano, bajo forma asociativa, que propicie el debate y la reflexión sobre los problemas comunes, facilite el intercambio de información y experiencias, garantice la coordinación de iniciativas y, en definitiva, fomente la cooperación entre universidades iberoamericanas» $»^{44}$. Y, a su vez, «[c] omo objetivo fundamental se propone la consolidación de un espacio iberoamericano de educación superior, para lo que se promoverá una reflexión permanente sobre sus problemas, se impulsará la información y comunicación así como la cooperación entre las instituciones universitarias de los diferentes países, se fomentará la movilidad de profesores y estudiantes con reconocimiento de estudios y la realización de programas de doctorados compartidos en relación con la creación y fortalecimiento de redes de investigación ${ }^{45}$. Pues bien, a la postre, el CUIB ha pasado a convertirse en un organismo central del EIC al integrar la Unidad Coordinadora junto con la OEI y la SEGIB, lo que pone de manifiesto las sinergias entre el nivel político y el nivel académico en el impulso y desarrollo del EIC.

Sobre la base de estos antecedentes, las ministras y ministros de Educación de los países iberoamericanos, reunidos en Toledo en 2005 en el seno de la Conferencia Iberoamericana de Educación ${ }^{46}$ con carácter previo a la Cumbre Iberoamericana de Salamanca del mismo año, dieron el espaldarazo definitivo a la idea de crear un espacio común cooperación universitaria en Iberoamérica, que desde este momento recibe el nombre de Espacio Iberoamericano del Conocimiento ${ }^{47}$. De este modo, se allanó el terreno para que tres meses más tarde

-Alentar la conformación de redes, especialmente sur-sur.

- Prestar especial atención a la formación de doctores (a través de becas y programas compartidos que combinen enseñanza presencial y virtual).

- Prestar atención preferente a la movilidad (por la experiencia formativa que implica y por su contribución a la creación del espacio académico iberoamericano).

- Apoyar proyectos interuniversitarios en el campo de la acreditación y evaluación y promover acuerdos que faciliten el reconocimiento parcial de estudios.

43 La Conferencia tuvo lugar entre el 29 de abril y el 1 de mayo de 2002.

44 Declaración final de la Conferencia, párrafo tercero. La cursiva es añadida.

45 Declaración final de la Conferencia, párrafo cuarto. La cursiva es añadida.

46 XV Conferencia Iberoamericana de Educación, Toledo, 12 y 13 de julio de 2005.

47 Las ministras y ministros deciden «[e]levar a la XV Cumbre de Salamanca [su] voluntad de avanzar en la discusión y concertación para crear un espacio iberoamericano del conocimiento articulado en torno a la necesaria transformación de la educación superior, la investigación, el desarrollo y la innovación, que dé respuesta a las necesidades de los países iberoamericanos» (Declaración de Toledo 
la XV Cumbre Iberoamericana, reunida en Salamanca los días 13 y 14 de octubre de 2005, acordase «avanzar en la creación de un Espacio Iberoamericano del Conocimiento, orientado a la necesaria transformación de la Educación Superior, y articulado en torno a la investigación, el desarrollo y la innovación, condición necesaria para incrementar la productividad brindando mejor calidad y accesibilidad a los bienes y servicios para nuestros pueblos así como la competitividad internacional de nuestra región» ${ }^{48}$. En cumplimiento del mandato presidencial, la siguiente Conferencia Iberoamericana de Educación adoptó en Montevideo un documento anexo a la Declaración Final con la única finalidad de sentar las bases y poner en marcha el EIC ${ }^{49}$. Para ello, realiza con amplitud una exposición de los fundamentos, antecedentes, caracterización y líneas prioritarias de actuación del EIC. Se trata, por tanto, del documento de base del EIC, pues si bien en Salamanca se habían esbozado los elementos del EIC, no sería hasta el año siguiente en Montevideo que se perfilaría su concepto y se profundizaría en sus contenidos y líneas de acción. En este sentido, se define el EIC como el «ámbito en el cual promover la integración regional y fortalecer y fomentar las interacciones y la cooperación para la generación, difusión y transferencia de los conocimientos sobre la base de la complementariedad y el beneficio mutuo, de manera tal que ello genera una mejora de la calidad y pertinencia de la educación superior, la investigación científica e innovación que fundamente un desarrollo sostenible de la región $»^{50}$. En paralelo a la conceptualización y configuración del EIC, en Montevideo también se adopta la primera medida concreta como es la elaboración de un Programa Cumbre de

de 13 de julio de 2005, apartado 6 - la cursiva es añadida-). El texto de este artículo pasó casi en su integridad al apartado 13 de la Declaración Final de la Cumbre de Salamanca de 14 de octubre de 2005.

48 Declaración de Salamanca, apartado 13.

49 Este documento, que lleva por título «Espacio Iberoamericano del Conocimiento», se elaboró a partir de «las aportaciones y conclusiones de un Encuentro de expertos iberoamericanos celebrado en Sevilla el 8 y 9 de Febrero de 2006 y las recibidas de las instituciones responsables de la elaboración de la iniciativa, el Consejo Iberoamericano de Universidades (CUIB), la Organización de Estados Iberoamericanos (OEI) y la Secretaría General Iberoamericana (SEGIB). A ello se han sumado los mecanismos de consulta desarrollados por el CUIB y la Reunión de viceministros y responsables de educación superior e investigación convocada por la OEI celebrado en Buenos Aires el 29 y 30 de mayo de 2006» (apartado 1 del Documento).

50 Apartado 4 del documento de base, «Caracterización del Espacio Iberoamericano del Conocimiento». Sobre la base de este concepto es evidente la interrelación entre el EIC y la integración, al igual que en la creación del CUIB. Todo ello porque la integración es un concepto inherente a las relaciones internacionales en el espacio iberoamericano y un proyecto de la envergadura regional del EIC no sólo no puede ser ajeno a ello, sino que debe establecer un vínculo privilegiado. Sin embargo, en la práctica, este vínculo todavía no se ha desarrollado adecuadamente, pues, por ejemplo, no se han establecido mecanismos de participación de órganos comunitarios en la estructura funcional del EIC. En este sentido, la propia Declaración de Montevideo concluye que la educación superior y la investigación son «herramientas privilegiadas para impulsar procesos de integración entre los países, para la generación y transferencia de conocimiento relevante, local, regional y global, así como para la formación de profesionales con pertenencia y visión iberoamericanas» (Considerando 10 -vid. también apartado 2 del Documento de base, último párrafo-). 
Cooperación en materia de movilidad académica de estudiantes de posgrado ${ }^{51}$, que al año siguiente en Santiago de Chile 2007 se aprobaría bajo el nombre Pablo Neruda ${ }^{52}$, que vendría a complementar al Programa de Intercambio y Movilidad Académica de la OEI (PIMA) ${ }^{53}$ creado en 1999 para la movilidad de estudiantes de grado o pregrado ${ }^{54}$. De este modo quedaría cubierta la movilidad en todos los niveles académicos y entre todos los países iberoamericanos ${ }^{55}$.

En suma, si bien el EIC nace en 2005 cargado de una cierta dosis de verbalismo derivado del discurso iberoamericano propio de las Cumbres, no es menos cierto que se ha venido configurando sobre la base de fuertes sinergias prexistentes de cooperación política y académica, las cuales pueden expresarse en los cuatro resultados más significativos alcanzados en investigación (CYTED), en movilidad (Mutis) y en garantía de la calidad (RIACES) y en asociacionismo interuniversitario y creación de redes. Sobre estas sólidas y fructíferas bases, el diseño y configuración del EIC entre los años 2005 y 2007 ha seguido un patrón de progresiva definición de objetivos -empezando por la propia conceptualización del EIC-, de fortalecimiento institucional y de establecimiento de líneas de acción que se han ido consolidando paulatinamente.

\footnotetext{
51 Los máximos responsables de educación acordaron «[e]levar a la XVI Cumbre Iberoamericana de jefes de Estado y de gobierno, como primera medida en la puesta en marcha del EIC, la solicitud de impulsar un Programa Cumbre de Cooperación en materia de movilidad académica de estudiantes, que se sustente en criterios básicos de pertinencia, calidad y multilateralidad y tome en cuenta los antecedentes que a este respecto se han venido desarrollando en la región» (Declaración de Montevideo de 14 de julio de 2006, apartado 12).

52 Programa de Acción de Santiago de Chile, 10 de noviembre de 2007, apartado 9. Puede accederse a la información del Programa a través del sitio web http://www.espaciodelconocimiento.org/neruda/.

53 http://www.oei.es/pima/.

54 «La OEI inició en 1999 una línea de cooperación en educación superior. Como acción prioritaria se centró en el diseño, puesta en marcha y ejecución del Programa de Intercambio y Movilidad Académica (PIMA) que puede ser considerado la matriz y antecedente más sólido de movilidad de estudiantes de grado, con reconocimiento de los estudios, en el ámbito iberoamericano. La movilidad de estudiantes se revela como estrategia política para las aspiraciones de integración en nuestra región, y es una herramienta fundamental para avanzar en la armonización entre los sistemas de educación superior» (Documento de base del EIC, apartado 3, párrafo séptimo).

55 En relación con la movilidad académica iberoamericana en general, y el programa Pablo Neruda en particular, véase, entre otros, DELPIANO LIRA, C.: «El programa de movilidad estudiantil de postgrado Pablo Neruda: análisis y perspectivas», en SOBRINO HEREDIA, J. M.; ALCAIDE FERNÁNDEZ, J.; PUREZA, J. M. (eds.): Innovación y conocimiento, cit., pp. 303-318. Según información de la OEI, durante el período 2013-2014 «se desarrollará y finalizará la primera convocatoria ordinaria del Programa de movilidad Pablo Neruda y se convocará la segunda. Durante este período se llevarán a cabo un mínimo de 548 movilidades, de docentes y estudiantes pertenecientes a 54 universidades, agrupadas en siete redes. La nueva convocatoria debería aspirar a doblar el número de movilidades, alcanzando como mínimo el millar. El Programa de Intercambio y Movilidad Académica (PIMA) continuará desarrollándose merced al apoyo recibido de la Junta de Andalucía. Las 84 movilidades realizadas en 2012, correspondientes a las 25 universidades participantes, se verán mantenidas o incrementadas en función de la disponibilidad presupuestaria de los patrocinadores» (ORGANIZACIÓN DE ESTADOS IBEROAMERICANOS: Memoria 2011-2012. Programa Presupuesto 2013-2014, Madrid, 2012, p. 175).
} 


\section{2.-LA CRECIENTE CONSOLIDACIÓN DEL EIC}

Con la fuerza y aparente claridad con la que nace el EIC en Salamanca y se desarrolla en Montevideo, pudiese parecer que desde entonces hasta ahora no ha hecho más que fortalecerse. Y ello es cierto, pero no con la intensidad con que se perfiló en 2005 y 2006 pues, sin ir más lejos, la Declaración final de la Cumbre de Santiago de Chile de 2007 no contiene una sola referencia al EIC, ni a la educación superior, ni siquiera a la educación en general. En contrapartida, como acabamos de señalar, el Plan de Acción de Santiago incluye como gran novedad la creación del programa Pablo Neruda.

Desde su formulación oficial en 2005, se han venido dado pasos que responden a un procedimiento que goza de cierta coherencia ${ }^{56}$. En particular, por un lado, se ha ido perfilando el horizonte al que se quiere llegar, estableciendo como tal horizonte el propio EIC, en tanto que noción que encarna el objetivo integral de la cooperación interuniversitaria iberoamericana en todos los planos que hemos calificado como integrantes de un «espacio común de cooperación universitaria»: la investigación, la movilidad académica, el reconocimiento académico, la garantía de la calidad, las titulaciones conjuntas y las redes temáticas. Por otro lado, al servicio del EIC se ha dispuesto una estructura institucional jerarquizada e integradora de actores políticos, técnicos y académicos articulada en torno a dos niveles. En el nivel político, la toma de decisiones está cubierta en todos los niveles posibles, desde los Presidentes - Cumbres Iberoamericanas- hasta los responsables de educación superior e investigación -Foro Iberoamericano de Responsables de Educación Superior (FIRES) - pasando por los propios ministros de Educación - Conferencias Iberoamericanas de Educación-. Merece una atención especial la figura del FIRES, en la medida en que su creación responde exclusivamente a la finalidad de crear el EIC $\mathrm{EI}^{57}$, lo que le ha convertido en uno de los principales artífices de los avances conseguidos en el proceso de consolidación.

El origen del FIRES se encuentra en 2007, paradójicamente el mismo año en que la Cumbre de Santiago de Chile guardó silencio sobre el EIC. Ese año, la Unidad Coordinadora convocó la I Reunión de Responsables de Educación

\footnotetext{
56 Esta cierta coherencia se torna en un elemento de solidez frente al resto de iniciativas de creación de espacios comunes en los que no se aprecia un procedimiento que permita afirmar una estrategia coherente para la consecución de los objetivos perseguidos, como señalados en el apartado I.

57 La primera vez que se propone su creación es en el informe de la SECIB sobre Análisis y potencialidades de la cooperación iberoamericana en educación superior, en el que se afirma que «[c]on el objeto de tener un foro especializado en educación superior, se puede institucionalizar un Foro Iberoamericano de Responsables de las Políticas de Educación Superior (FIRES). Este Foro se concibe como un espacio para el análisis, la elaboración de estudios y el diseño de recomendaciones sobre políticas. Se favorecería así, la interrelación y la convergencia de los sistemas de la educación superior en el ámbito iberoamericano» (apartado 7.1, párrafo sexto).
} 
Superior ${ }^{58}$, con la finalidad de elaborar la Hoja de Ruta o Plan Estratégico del EIC $^{59}$ sobre la base de criterios generales que persiguen atender las asimetrías, la heterogeneidad y la diversidad regional, tales como la solidaridad, la complementariedad y la concertación. Los tres aspectos más reseñables de la reunión ${ }^{60}$ ponen de manifiesto tres valores centrales del EIC: el realismo, la identidad y la integración. En primer lugar, se parte de la necesidad de contar con «un mapa lo más ajustado posible a la realidad $»^{61}$ de las experiencias existentes en la región, lo que pone de manifiesto, una vez más, que el EIC no se va fraguando sobre el vacío ni a vista de pájaro, sino sobre la referencia constante y próxima a la realidad universitaria iberoamericana ${ }^{62}$. En segundo lugar, se persigue fomentar la visión iberoamericana en las acciones de movilidad, de formación y de investigación, en todos los niveles de grado y posgrado, jóvenes investigadores, doctorado y posdoctorado, en correspondencia con los fundamentos de identidad histórica y cultural que singularizan a la Comunidad Iberoamericana de Naciones. Y, en tercer lugar, se confiere al EIC una vocación integradora en toda la región, en el sentido de que se estableció la necesidad de «incorporar los programas que existen desde las distintas instancias de integración iberoamericanas (Red Especializada de Ciencia y Tecnología - RECyT de MERC—SUR,

58 La reunión tuvo lugar los días 5 y 6 de julio en Bogotá.

59 Esta propuesta inicial formulada en esta primera reunión se irá desarrollando en las sucesivas, ya bajo el nombre de Foro Iberoamericano de Responsables de Educación Superior (FIRES) desde la reunión en Antigua en 2008, hasta lograr finalmente un completo Documento sobre la Estrategia del EIC, aprobado por el V FIRES en 2011, al que nos referiremos infra.

60 En esta reunión se abordaron diversos aspectos vinculados con la garantía de la calidad del sistema universitario, con la investigación y con la formación y la movilidad, entre otros (cfr. Informe de la Reunión de Responsables de Educación Superior de los países iberoamericanos para elevar a la XVII Conferencia Iberoamericana de Educación, disponible en: http://www.cuib.org/documentos/documentos/InformeReunionBogota_EIC.pdf).

61 Informe de la Reunión de Responsables de Educación Superior de los países iberoamericanos para elevar a la XVII Conferencia Iberoamericana de Educación, p. 2. La cursiva es añadida.

62 En esta labor el EIC y la UNESCO van de la mano, como se puso de manifiesto en el II FIRES en que se destacó «especialmente la alianza estratégica que existe con el IESALC, como pieza central para el desarrollo del EIC» (Informe del II Foro Iberoamericano de Responsables de Educación Superior, Ciencia e Innovación, 17-18 de julio de 2008, Antigua Guatemala, p. 1). En efecto, esta propuesta debe ponerse directamente en relación con el acuerdo de la Conferencia Regional de Educación Superior de la UNESCO de 2008 (CRES 2008), en virtud del cual es estableció la necesidad de llevar a cabo «la articulación de los sistemas nacionales de información sobre Educación Superior de la región para propiciar, a través del Mapa de la Educación Superior en ALC (MESALC), el mutuo conocimiento entre los sistemas como base para la movilidad académica y como insumo para adecuadas políticas públicas e institucionales.» (Declaración final, CRES 2008, 4-6 de junio, Cartagena de Indias). La CRES 2008 fue organizada por el Instituto Internacional de la UNESCO para la Educación Superior en América Latina y el Caribe (IESALC) y por el Ministerio de Educación Nacional de Colombia. IESALC fue la institución que asumió el encargo de elaboración del MESALC, el cual, desde 2010, se asoció al proyecto INFOACES en virtud del cual se persigue crear un ambicioso sistema integral de información sobre todas las instituciones de educación superior de América Latina. El proyecto INFOACES cuenta con financiación de la Comisión Europea a través del programa ALFA III, y reúne a 32 socios de 22 países - 17 de América Latina y 5 de Europabajo la coordinación de la Universitat Politècnica de València, a través del Centro de Gestión de la Calidad y del Cambio (www.infoaces.org). 
Comisión de Ciencia y Tecnología de Centroamérica y Panamá —CTCAP,...). Igualmente el relevamiento debe incorporar las acciones que se han formulado desde el Convenio Andrés Bello, UNESCO- Montevideo, OEA y demás organismos internacionales con competencias en ciencia y educación superior ${ }^{63}$.

En pro de la consecución del EIC, el FIRES ha aprobado en fechas recientes, como avanzábamos, un Documento sobre la Estrategia del EIC con medidas concretas y realistas con la finalidad de fijar el rumbo del proceso. En efecto, en la quinta reunión del Foro que tuvo lugar en $2011^{64}$, se aprobó por unanimidad este documento estratégico en el que se pone énfasis en una mayor y más completa institucionalización del proceso, con la consolidación de la Oficina del EIC - a la que nos referiremos Infra-, así como con la creación de un Consejo de Programas que articule las acciones de cooperación iberoamericana tratando de aprovechar las sinergias entre los diversos Programas de Cooperación. Asimismo, se formuló una propuesta inicial de creación de un sistema de movilidad de estudiantes que se ha sometido a consideración de los países; y se volvió a insistir en la necesidad de hacer el seguimiento al espacio ALCUE, para lo que se aprobó una línea de trabajo que también trate de identificar una contraparte europea del FIRES.

Las más recientes aportaciones del FIRES al desarrollo y a la consolidación del EIC no pueden ser más contundentes en la medida en que nos ponen ante un proceso que ha llegado a un punto de no retorno. Así se puso de relieve en la última reunión del FIRES que tuvo lugar en 2012 en $\mathrm{Cádiz}^{65}$-con ocasión del Bicentenario de la Constitución de 1812-, la cual puede además considerarse como la más fructífera, pragmática y realista de todas cuantas se han celebrado hasta la fecha para desarrollar el EIC. Por lo que se refiere a su consideración como un proceso irreversible, en la Declaración de Cádiz los máximos responsables de la educación superior, la ciencia y la innovación ratificaron «aún más si cabe [su] compromiso con la construcción de un [EIC]», al tiempo que se afirma que «aparece ya como una realidad incuestionable ${ }^{66}$. A su vez, se destacó la necesidad de establecer plazos claros y mecanismos de evaluación de los avances, así como la necesidad de avanzar

63 En relación con el vínculo entre el EIC y la integración, debe destacarse la creación, a propuesta de la OEI, de «un Centro de Altos Estudios Universitarios Iberoamericano, institución que se propone contribuir decisivamente a la integración y desarrollo regional, a la mejora de la cualificación de nuestros jóvenes y a la efectiva constitución del Espacio Iberoamericano del Conocimiento (EIC) e incorporar esta propuesta en el Programa de Acción Presidencial a ser adoptado en el marco de la XVIII Cumbre Iberoamericana» (XVIII Conferencia Iberoamericana de Educación, Salinillas (El Salvador), 19 y 20 de mayo de 2008, Declaración de El Salvador, apartado 7. La cursiva es añadida.).

${ }_{64}$ V Foro Iberoamericano de Responsables de Educación Superior, La Habana, 15 y 16 de septiembre de 2011.

65 VI Foro Iberoamericano de Responsables de Educación Superior, Cádiz, 25 a 27 de julio de 2012.

66 La cursiva es añadida. 
en un reconocimiento más eficiente de períodos de formación académica en pro de la movilidad ${ }^{67}$. En este sentido, se hace hincapié en un aspecto muchas veces descuidado, como es el de la necesidad de que los Estados no sólo no pongan trabas a la movilidad de personas dentro del EIC, sino que incluso establezcan mayores facilidades para hacerlo factible ${ }^{68}$. Por ello resulta tan importante la vinculación que el EIC pueda establecer con los procesos de integración, en la medida en que resulta inherente a éstos la libre circulación de personas, aunque todavía sigan existiendo diversas dificultades ${ }^{69}$. De igual modo, se centró la atención en el postgrado como área estratégica a corto y medio plazo para impulsar la formación de doctores ${ }^{70}$ para la implementación de programas de investigación tanto en Universidades, como en centros de investigación y empresas ${ }^{71}$. Pero son sobre todo tres los resultados a resaltar

67 En materia de reconocimiento de títulos, el gran impulso se produjo en la Reunión Extraordinaria del FIRES (Mar del Plata, 2 de diciembre de 2010): «con el objeto de alcanzar un acuerdo sobre el reconocimiento de títulos en la región; en virtud de la necesidad de superar las debilidades presentadas por el Convenio Regional de Convalidación de Estudios, Títulos y Diplomas de Educación Superior en ALC de 1974 [...] considerando avances como los registrados en el ámbito del MERCOSUR Educativo, en el cual se han alcanzado importantes acuerdos en las negociaciones para vincular los resultados de la acreditación en el marco del Sistema ARCUSUR con la reválida de los títulos; vistos los avances en el ámbito latinoamericano, donde se constata una tendencia hacia la firma de convenios bilaterales de reconocimiento de estudios de ES basados en los resultado de los mecanismos nacionales de aseguramiento de la calidad; DECLARAN:

-Que el reconocimiento mutuo de títulos, diplomas y grados de educación superior en la región constituye un elemento central para el desarrollo del EIC.

- La disposición de avanzar en un mecanismo ágil de dicho reconocimiento en la región basado en los sistemas nacionales de aseguramiento de la calidad.

- La decisión de fortalecer estos sistemas nacionales de calidad.

—La voluntad de impulsar la suscripción de acuerdos de reconocimiento de educación superior basado en dicho esquema».

La importante contribución del FIRES al reconocimiento de títulos fue reconocida por la XX Conferencia Iberoamericana de Educación, celebrada en Buenos Aires el 13 de septiembre de 2010, en la que los Ministros destacaron «los progresos realizados para el reconocimiento académico de los periodos de estudio en el marco del Espacio Iberoamericano del Conocimiento (EIC), y el papel que en ello ha desempeñado el Foro Iberoamericano de Responsables de Educación Superior, Ciencia e Innovación en la promoción de un Acuerdo Marco y el impulso de convenios bilaterales en ese ámbito» (Declaración final, apartado 5).

68 «El [EIC] se constituye como un espacio de movilidad para el intercambio, no sólo de Ciencia y de la Tecnología, o de las iniciativas emprendedoras, sino también de las personas, de las ideas y de la dimensión social y cultural de nuestros países. Esta movilidad no es más que el reflejo de la realidad multicultural que conforma la comunidad iberoamericana de naciones, y que funde sus raíces en un pasado histórico común» (Declaración de Cádiz, 27 de julio de 2012).

69 A este respecto, véase, entre otros, GOIZUETA VÉRTIZ, J.; GÓMEZ FERNÁNDEZ, I.; GONZÁLEZ PASCUAL, M. I. (Dirs.): La Libre Circulación de Personas en los Sistemas de Integración Económica: Modelos Comparados. Unión Europea, Mercosur y Comunidad Andina, Edit. Thomson Reuters Aranzadi, Cizur Menor, 2012.

70 De esta forma, se retoma la propuesta del Programa de Formación de Doctores formulada en la III Reunión del FIRES (Buenos Aires, 5 de junio de 2009).

71 En este sentido, se perseguirá la consolidación y expansión de los programas Pablo Neruda, el Programa Iberoamericano de Innovación y el de Propiedad Industrial, así como la revisión y el nuevo impulso del CYTED y el proyecto IberVirtual. 
de esta reunión: la aprobación del Plan de Trabajo de la Estrategia del EIC, el impulso a la realización de Encuentros Nacionales que incorporen a distintos actores y agentes del EIC; y el apoyo a la creación de la Red Iberoamericana de Excelencia Científica en Biotecnología ${ }^{72}$.

En el nivel técnico, el proceso político-diplomático de cumbres y conferencias iberoamericanas y del FIRES se ve apoyado por la denominada Unidad Coordinadora del $\mathrm{EIC}^{73}$, que ejerce una valiosa función de impulso y de coordinación, y está integrada por la OEI, por la SEGIB y por el CUIB ${ }^{74}$. Así, el EIC cuenta con una nueva fortaleza frente a otros espacios comunes ${ }^{75}$ al integrar a las universidades en la tríada de instituciones que impulsan y coordinan el EIC. Más recientemente, en 2010, la Conferencia Iberoamericana de Educación instó a la Unidad Coordinadora a crear una Oficina del EIC con la finalidad de reforzar los mecanismos de coordinación y la capacidad operativa ${ }^{76}$, dotando así al proceso

72 XXII Conferencia Iberoamericana de Educación, Salamanca, 6 de septiembre de 2012, Declaración final, apartado 14.

73 El germen de esta Unidad Coordinadora se encuentra en la XV Conferencia Iberoamericana de Educación, en la que las ministras y ministros iberoamericanos acuerdan «[s]olicitar a la Secretaría General Iberoamericana que, junto con la Organización de Estados Iberoamericanos y el Consejo Universitario Iberoamericano, en articulación con los mecanismos de cooperación en educación superior desarrollados y en los ámbitos regionales y subregionales, pongan en marcha el proceso de concertación político-técnica para concretar esta propuesta, sobre la base de los principios y líneas expuestas en el documento «Hacia un Espacio Iberoamericano del Conocimiento» debatido en esta Conferencia y en los objetivos establecidos en ALCUE» (Declaración de Toledo de 13 de julio de 2005, apartado 7 -la cursiva es añadida-). Debe llamarse la atención acerca del hecho de que el EIC nace en relación con ALCUE, hecho sobre el que volveremos más adelante.

74 Así, la Unidad Coordinadora del EIC está compuesta nada menos que por dos Organizaciones Internacionales -OEI, SEGIB- y por una organización no gubernamental interuniversitaria -CUIB-que supone, por tanto, la incorporación y participación directa de las Universidades al proceso de creación y de desarrollo del EIC.

75 Estos procesos son aparentes frutos de un irreflexivo ímpetu político, expresado en un apetito llamativamente desordenado por alcanzar el mito de la convergencia y sin apenas la participación de la comunidad académica, e incluso con su posición en contra, y sin contar con análisis o estudios previos.

76 XX Conferencia Iberoamericana de Educación, Declaración de Buenos Aires de 13 de septiembre de 2010, apartado 17. Otro aspecto muy significativo de esta XX Conferencia es la aprobación del Programa de Dinamización del EIC, en calidad de Programa compartido del Programa Metas Educativas 2021 aprobado en tal ocasión para «hacer frente a los retos pendientes del siglo XX, sobre todo en el campo de la alfabetización y educación básica de jóvenes y de adultos, del acceso a la educación y de la calidad de la enseñanza, y a los desafíos del siglo XXI, especialmente en lo referido a la innovación, al desarrollo científico y tecnológico y a la incorporación a la sociedad de la información y del conocimiento» (Considerando 4). En relación con el EIC, el Programa Compartido X establece que un elemento fundamental para dinamizar el EIC es promover y apoyar las redes de investigación y de formación, lo que incluye el soporte a la movilidad de investigadores y estudiantes. Para ello, se adopta una estrategia que persigue, entre otras cosas, consolidar el Centro de Altos Estudios Universitarios de la OEI, potenciar el Observatorio Iberoamericano de la Ciencia y consolidar un sistema de movilidad de estudiantes con reconocimiento de estudios, así como de investigadores y docentes. A su vez, las principales líneas de acción se dirigen a potenciar el Programa Pablo Neruda, establecer mecanismos de coordinación entre instituciones en materia de movilidad, fomentar redes de excelencia o reforzar RIACES. 
de desarrollo del EIC una base organizativa sólida ${ }^{77}$. Esta Oficina, que dependerá funcionalmente de la Unidad Coordinadora y tendrá su sede en la $\mathrm{OEI}^{78}$, está llamada a ser una figura central en el futuro del EIC, tal y como se desprende del Documento sobre la Estrategia del EIC, aprobado por el V FIRES en 2011. En esta ocasión, los máximos responsables políticos de la educación superior en Iberoamérica solicitaron a Argentina, Cuba, Colombia, México y Nicaragua que acompañasen a la Oficina en su proceso de consolidación y de elaboración de un Plan de Trabajo y la creación de mesas de trabajo sobre temas específicos; al tiempo que se le encomendó la labor de prestar su apoyo para reforzar la cooperación países extrarregionales ${ }^{79}$.

Los últimos avances han tenido lugar en la Cumbre de Cádiz de $2012^{80}$, cuya Declaración, sin embargo, no contiene ninguna referencia expresa al EIC, limitándose a «[f]omentar el intercambio educativo, en particular a nivel superior y tecnológico: promover la participación y actualización de una oferta académica de calidad en el sistema educativo, especialmente en las universidades y otros centres de educación superior; y en este marco, estimular esquemas de cooperación y entendimiento que posibiliten el efectivo reconocimiento recíproco de grados y títulos $»^{81}$. Ahora bien, como vimos, los grandes avances en el EIC no han venido tanto de la mano de las Cumbres Iberoamericanas como de las Conferencias Iberoamericanas de Educación, del FIRES, o incluso de las propias redes de Universidades.

\section{III.-CONSIDERACIONES FINALES}

A día de hoy, siguen siendo válidas las dos constantes que han venido caracterizando la cooperación universitaria iberoamericana: una decidida voluntad política y académica de cooperar pero una indefinición del horizonte al que se quiere llegar, pues aunque el EIC puede considerarse un horizonte definido, lo cierto es que coexiste con otros a los que los mismos Estados también quieren llegar, como ENLACES y, en menor medida, ALCUE.

En principio, las estructuras más viables para la convergencia educativa son las más consolidadas en el terreno económico-político, es decir, procesos de integración, en conexión con su dimensión social creciente en la que encaja la educación. En este sentido, la UE sí podría llegar a servir de ejemplo de cómo un

\footnotetext{
77 ORGANIZACIÓN DE ESTADOS IBEROAMERICANOS: Memoria 2011-2012. Programa Presupuesto 2013-2014, cit., p. 175.

78 Ibídem.

79 Así, por ejemplo, se previó su colaboración en la organización del III Encuentro IberoaméricaRusia (México D.F., 2012). Vid. Nota de prensa de la SEGIB, http://segib.org/es/node/5932.

80 XXII Cumbre Iberoamericana, Cádiz, 16-17 de noviembre de 2012.

81 Declaración de Cádiz, 17 de noviembre de 2012, apartado 7.
} 
proceso de integración favorece una ciudadanía comunitaria en la que se facilita jurídica y administrativamente la movilidad académica a través de la libertad de circulación. De ahí que tanto los documentos como las instituciones y programas o iniciativas emprendidos tome como referente a la integración.

Una de las claves para determinar el nivel óptimo al que ha de plantearse un espacio común es atender al criterio de necesidad o de optimización. Es decir, tendrá más posibilidades de concretarse aquel espacio que sea «necesario»o que, sin serlo, se lleve a cabo en el nivel óptimo o más adecuado posible. El nivel de optimización o de mejor adecuación tiene que establecerse a partir de la cohesión, sobre la base de valores y de intereses comunes sólidos: en materia de educación, es evidente que esos valores e intereses han de responder a unos lazos históricos y culturales especialmente estrechos. Es lo que sucedió en Europa con el EEES, y es lo que sucede con el EIC e incluso con un potencial ENLACES, y es por tanto también lo que podría dificultar o convertir en quimérico un eventual ALCUE, y más aún en un contexto internacional en el que las diferencias políticas entre América Latina y Europa están haciéndose cada vez mayores.

Por lo visto, resulta evidente que ENLACES nace y crece por referencia al EIC, lo que nos permite aventurar en escenario de cooperación iberoamericana y caribeña con grandes visos de ir prosperando, si bien lentamente. Sin embargo, también es muy probable un escenario en el que el EIC y el ALCUE estén condenados a entenderse, no sólo porque los principales actores, las Universidades, difícilmente van a adoptar ninguna posición excluyente en relación con cualquiera de ellos - como demuestran las distintas declaraciones de reuniones de Rectores-, sino porque el propio EIC, como vimos, nace con vocación de compatibilidad con las propuestas que surjan del entorno latinoamericano, como ALCUE. En fin, el EIC discurre con gran autonomía y solidez entre dos aguas, entre un ENLACES creciente y un ALCUE menguante, y sin duda la decisión de hacia donde se incline la balanza está, a día de hoy, en manos de los países latinoamericanos.

Por ello, en mi opinión, el EIC es el que tiene la mejor posición de salida para lograr consolidarse en este entorno tan revuelto al contar con una serie de fortalezas que lo singularizan. El valor añadido del EIC frente a otras iniciativas vendría dado por la existencia de una comunidad histórica - la Comunidad Iberoamericana de Naciones- que favorece la solidaridad; por una dilatada y fructífera experiencia en diversos ámbitos de la cooperación universitaria como la investigación (CYTED), la movilidad (Mutis/PIMA/Pablo Neruda) o los sistemas de garantía de calidad (RIACES); por el establecimiento de la integración como punto de referencia para la implementación de la cooperación, especialmente por lo que se refiere a los sistemas de movilidad; y por un completo marco institucional para la toma de decisiones en el que están representados todos las 
instancias políticas y académicas implicadas, donde actúan los Presidentes-reunidos en las Cumbres Iberoamericanas-, los Ministros - reunidos en las Conferencias Iberoamericanas de Educación-, los máximos responsables de la educación superior, la ciencia y la innovación - reunidos en el FIRES-, de forma razonablemente bien cohesionada gracias a la acción de la Unidad Coordinadora -OEI, SEGIB y CUIB - y con el apoyo de una Oficina del EIC en ciernes. Ahora bien, sin duda el camino no está libre de obstáculos ni nos encontramos ante un proceso inmaculado, pues no son pocas las dificultades derivadas de la condicionalidad política que marca el nivel de intensidad de los compromisos, el verbalismo y la lentitud en la implementación de los distintos programas e iniciativas, cuyo impacto y financiación son muchas ocasiones deficitarios. 